\title{
Postmarket safety of drugs approved by Health Canada on the basis of clinical and surrogate outcomes: a cohort study
}

\author{
Joel Lexchin MSc MD, Tareq Ahmed B. Pharm MPH
}

Abstract

Background: Health Canada approves drugs on the basis of evidence from clinical trials using clinical or surrogate outcomes. This study compares the postmarket safety of these 2 groups of drugs.

Methods: Information about whether clinical or surrogate outcomes were used and the date of market approval were obtained from Health Canada's Summary Basis of Decision documents issued from Jan. 1, 2005, to Dec. 31, 2014. Safety warnings and the dates they were issued were identified through advisories on the MedEffect Canada website. Kaplan-Meier survival curves were calculated to determine the likelihood that drugs in the clinical and surrogate outcome groups would receive a serious safety warning. The time from market authorization to first serious safety warning was compared for the 2 groups of drugs.

Results: A total of 124 drugs were approved by Health Canada using clinical outcomes and 114 using surrogate outcomes. KaplanMeier curves did not differ between the 2 groups $(p<0.9)$. The median time from market authorization to first serious safety warning was 722 days in the clinical outcome group and 818 days in the surrogate outcome group (difference 96 days, $95 \%$ confidence interval -295 to 425$)$.

Interpretation: We found no statistically significant difference in postmarket safety between drugs approved using clinical outcomes and those approved using surrogate outcomes. Because drugs in the surrogate outcome group are approved before their benefit:harm ratio is fully established, these drugs should be used with caution until their clinical benefits are better understood.

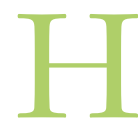
ealth Canada approves drugs on the basis of clinical trials that use clinical outcomes, surrogate outcomes or a combination of both. The use of surrogate outcomes is attractive to many groups involved with pharmaceutical products, including the pharmaceutical industry, regulators, health care practitioners and patients. Their use allows trials to be done less expensively with fewer patients in a relatively short period, with the result that promising new drugs can reach patients faster. However, surrogate outcomes can fail to predict clinical effects accurately, and the effects of the intervention could be offset substantially by unintended, unanticipated or unrecognized mechanisms. ${ }^{1}$ Some drugs approved on the basis of surrogate outcomes have had serious safety problems and have had to be withdrawn from the market or have their indications substantially restricted. ${ }^{2-5}$

If drugs approved on the basis of surrogate outcomes are less safe than those approved on the basis of clinical outcomes, and possibly not as beneficial, their overall benefit:harm ratio will be less favourable and these drugs should be used with caution until their benefits are fully established. We conducted this study to compare the postmarket safety of drugs approved on the basis of clinical and surrogate outcomes. We determined the likelihood of a serious safety warning being issued by Health Canada and the time taken to recognize a serious safety issue for drugs in each group. In addition, we examined the time spent in the review process and the type of review (standard review, priority approval or Notice of Compliance with conditions) that the 2 groups of drugs underwent. We expected drugs approved in a shorter time to be more likely to receive a serious safety warning than those receiving a standard review. ${ }^{6,7}$ If drugs in the surrogate outcome group spend less time in the review process, that could account for more postmarket safety problems.

Competing interests: Joel Lexchin was chair of the board of Health Action International - Europe from 2011 to 2014 . No other competing interests were declared.

This article has been peer reviewed.

Correspondence to: Joel Lexchin, jlexchin@yorku.ca

CMAJ Open 2015. DOI:10.9778/cmajo.20150023 


\section{Methods}

Since Jan. 1, 2005, Health Canada has issued a Summary Basis of Decision document for each new drug it approves (www. hc-sc.gc.ca/dhp-mps/prodpharma/sbd-smd/drug-med/index -eng.php). The document outlines the clinical grounds used to grant market authorization. We obtained copies of all Summary Basis of Decision documents issued until Dec. 31, 2014, and read them independently to determine whether the clinical trials of the product used surrogate or clinical outcomes. Disagreements were resolved by discussion until consensus was reached. Clinical outcomes were defined as "a characteristic or variable that reflects how a patient [or consumer] feels, functions, or survives." ${ }^{8}$ Surrogate outcomes were defined as "a biomarker that is intended to substitute for a clinical endpoint. A surrogate endpoint is expected to predict clinical benefit (or harm or lack of benefit or harm) based on epidemiologic, therapeutic, pathophysiologic, or other scientific evidence." ${ }^{8}$ Only the outcomes defined as primary objectives in pivotal trials were used. Health Canada defines pivotal trials as "trials of high scientific quality, which provide the basic evidence to determine the efficacy, properties, and conditions of use of the drug." "If a drug was approved for one or more indications using both clinical and surrogate outcomes, we considered the approval to be based on clinical outcomes.

In addition to the type of outcomes used, we extracted the following additional information from the Summary Basis of Decision documents: the drug's generic and brand names, the company marketing the product, the therapeutic indication, the date of new drug submission (application to market the drug) and the date of Notice of Compliance (date of marketing authorization).

Information about the type of review process (standard review, priority approval or Notice of Compliance with conditions) came from annual reports that we obtained directly by contacting the Therapeutic Products Directorate and the Biologics and Genetic Therapies Directorate (at publications @hc-sc.gc.ca). For drugs approved after Apr. 1, 2013, we obtained additional information on the Notice of Compliance website (http://webprod5.hc-sc.gc.ca/noc-ac/index-eng.jsp).

We identified safety warnings and withdrawals of drugs for the period Jan. 1, 2005, to Dec. 31, 2014, by reviewing advisories for health professionals in the Recalls and Safety Alerts Database on the MedEffect Canada website (www.hc-sc.gc.ca/ dhp-mps/medeff/advisories-avis/prof/index-eng.php). According to Health Canada, this database is a comprehensive list of recalls, advisories and safety alerts. We recorded the date for each safety advisory or notice of withdrawal of a product. We included all serious safety advisories (defined as those using bold black print or boxed warnings, or both). We excluded advisories concerning the withdrawal of a specific batch or lot number because of manufacturing problems and those issued because of misuse of a drug (e.g., an unapproved use) or medication errors (e.g., a warning about remembering to remove a transdermal patch before applying a second one). If a drug received more than one serious safety warning, we used the date of the first warning. When necessary, notices on the
MedEffect website were supplemented by information we obtained by searching the product name in the Drug Product Database (http://webprod5.hc-sc.gc.ca/dpd-bdpp/index-eng. jsp). This database contains product-specific information on drugs approved for use in Canada as well as all products discontinued since 1996.

\section{Statistical analysis}

We calculated Kaplan-Meier survival curves for the period from receipt of market authorization to first serious safety warning or product withdrawal for drugs in each of the clini$\mathrm{cal}$ and surrogate outcome groups. We compared the curves using a log-rank (Mantel-Cox) test. A Kaplan-Meier analysis accounts for the fact that some drugs had received a safety warning and some had not by the end of the study period (Dec. 31, 2014).

The time from application for market authorization to receipt of approval and the time from receipt of approval to a safety warning or withdrawal from the market were calculated in days. We report means for the first period and compared them using a $t$ test. We report medians for the second period, because these values are not normally distributed (ShapiroWilk test), and compared them using the Mann-Whitney test. We compared the proportion of drugs in the 2 groups that were approved under the 3 different approval processes using the $\chi^{2}$ test. Counts were made of the number of clinical- and surrogate-outcome drugs approved for different therapeutic uses. A $p$ value of less than 0.05 was considered significant. We used Excel 2011 for Macintosh (Microsoft) and Prism 6.0 (GraphPad Software) for all calculations.

\section{Results}

We identified 251 drugs that had Summary Basis of Decision documents. We excluded 13 drugs: 5 were diagnostic agents, 5 were either bioequivalents or subsequent entry biosimilars and there were no outcomes documented, 2 were vaccines approved on an emergency basis and 1 was a disinfectant not used for treatment in humans. Of the remaining 238 drugs, $124(52.1 \%)$ were approved by Health Canada using clinical outcomes and 114 (47.9\%) using surrogate outcomes. The 238 drugs and their indications, the outcome used for approval and the classification of the outcome are listed in Appendix 1 (available at www.cmajopen.ca/content/3/3/E286/ suppl/DC1).

We found no difference in Kaplan-Meier curves between the 2 groups of drugs (Figure 1, $p<0.9$ ), which meant that the likelihood of drugs in each group acquiring a serious safety warning after they were marketed was the same. The median time to first serious warning was 722 days (interquartile range [IQR] 482 to 1257) for drugs in the clinical outcome group and 818 days (IQR 559 to 1556) for drugs in the surrogate outcome group, for a difference of 96 days ( $95 \%$ confidence interval [CI] -295 to 425 ).

The mean length of time in the review process was 465 days (95\% CI 420 to 510) for drugs in the clinical outcome group and 461 days (95\% CI 409 to 512) for drugs in the sur- 


\section{OPEN}

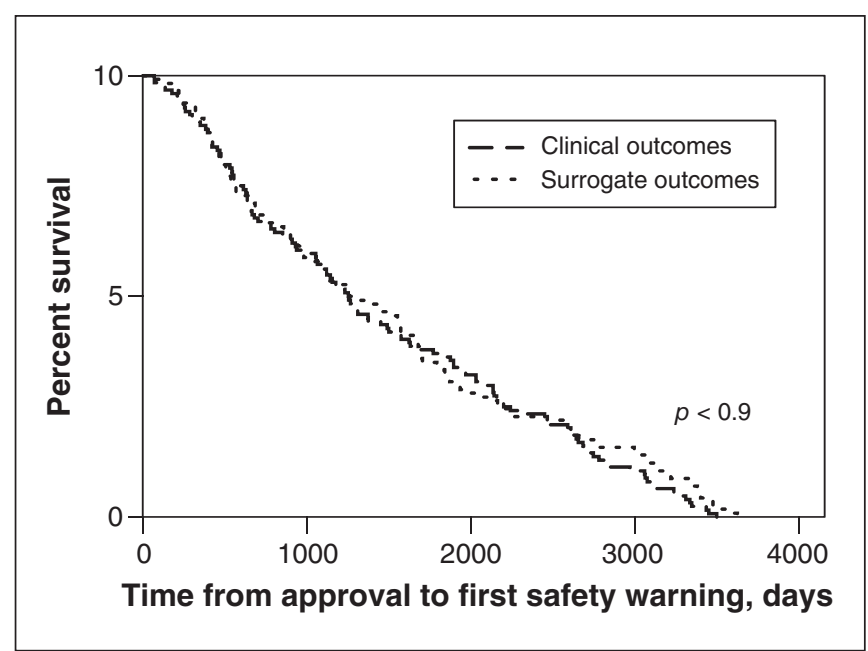

Figure 1: Kaplan-Meier curves showing time from approval to first serious safety warning or removal from market for drugs approved by Health Canada on the basis of clinical and surrogate outcomes.

rogate outcome group $(p<0.9)$. In the clinical outcome group, 101 drugs underwent a standard approval, 22 a priority approval, and 1 a Notice of Compliance with conditions. Respective figures for the surrogate outcome group were 67 , 29 and 18 (Table $1, p<0.001$ ).

Table 1 shows the distribution of therapeutic indications for the drugs in the clinical and surrogate outcome groups. Table 2 gives examples of outcomes for each group. Drugs for allergy, dermatology, genitourinary, gastrointestinal, "other" infectious diseases, neurology, psychiatry and rheumatology were more likely to be approved on the basis of clinical outcomes, whereas drugs for cancer, diabetes, hepatitis, HIV, inborn errors of metabolism and "other" metabolic diseases were more likely to be approved on the basis of surrogate outcomes. Twelve (33\%) of the 36 cancer drugs in the surrogate outcome group were approved under the Notice of Compliance with conditions process, whereas none of the 16 cancer drugs in the clinical outcome group used this approval process.

\section{Interpretation}

Based on the 2 measures of safety considered in this study the likelihood that Health Canada will issue a serious safety warning and the time from market approval to first serious safety warning - we found no statistically significant difference between drugs approved on the basis of surrogate outcomes and drugs approved on the basis of clinical outcomes. This is reassuring news in view of the anecdotal evidence about safety issues with some of the drugs in the surrogate outcome group. The comparable postmarket safety profiles may also reflect the equal time that the 2 groups of drugs spent in the review process. The speed of the review process has been associated with postmarket safety warnings. ${ }^{6,7,10,11}$

We need to recognize that the use of serious safety warnings is only an indirect measure of safety. The warnings do not measure the number of people potentially affected by safety problems nor the seriousness of the harms that the drugs cause. In addition, the information about safety from this study does not tell us whether the benefit:harm ratio is equivalent for the 2 groups of drugs. A recent meta-analysis found that clinical trials using surrogate outcomes were more likely to report larger treatment effects than trials reporting final clinical outcomes, a conclusion that could not be explained by differences in the risk of bias or characteristics of the 2 groups of trials. ${ }^{12}$ The Common Drug Review, through which the Canadian Agency for Drugs and Technologies in Health makes recommendations to federal, provincial and territorial drug plans about whether to fund a drug, felt that $28 \%$ of surrogate outcomes used in the trials that it assessed were not valid. ${ }^{13}$ These findings suggest that the benefit:harm ratio may be more robust for drugs with clinical outcomes than for some drugs with surrogate outcomes.

The different balance in the review processes between the clinical and surrogate outcome groups reflects the fact that trials of drugs for some high-priority indications are much more likely to have used surrogate outcomes. Of the 52 cancer drugs, $36(69 \%)$ were in the surrogate outcome group, and 12 of the 36 were approved with a Notice of Compliance with conditions. Similarly, all 9 drugs for HIV infection were in the surrogate outcome group, and 3 of these drugs were approved with a Notice of Compliance with conditions.

The finding that surrogate outcomes were used in the decision to approve $48 \%$ of new drugs is consistent with results from the US Food and Drug Administration and the European Medicines Agency. In the United States, pivotal trials using surrogate outcomes as their primary outcome formed the exclusive basis of approval for 91 (45\%) of 206 indications for 188 drugs. ${ }^{14}$ The European Medicines Agency evaluated 81 pivotal trials for 39 new products. No study measured a patient-relevant primary outcome for $21(54 \%)$ of the approvals (45 [56\%] of the trials). ${ }^{15}$

Whether surrogate outcomes should continue to be widely used for drugs for some therapeutic indications is open to question. Cancer drugs are frequently approved on this basis in multiple jurisdictions. ${ }^{16,17}$ Garattini and Bertele ${ }^{18}$ looked at 12 oncology drugs approved by the European Medicines Agency from 1995 to 2000. The outcomes for the clinical trials of these drugs tended to be subjective (e.g., "time to progression"), and there was seldom an evaluation of survival or quality of life. A second study examined 14 cancer drugs approved by the European Medicines Agency for 27 indications from January 1995 to December 2004. Only 2 of the 27 were supported by changes in overall survival, as compared with 13 for response rate, 11 for time to progression or progression-free survival, and 1 for "other."16 Tumour size does not correlate with overall survival, ${ }^{19}$ and the use of progression-free survival as a valid biomarker seems to depend on the type of cancer being treated. ${ }^{19-21}$ The continued use of surrogate outcomes as the basis for approval of drugs to treat noninsulin-dependent diabetes seems difficult to justify given the lack of correlation between a reduction in concentration of glycated hemoglobin and cardiovascular events. ${ }^{22}$ However, all 9 drugs approved for this indication were in the surrogate outcome group. 


\section{Limitations}

There are 3 major limitations to our study. First, we based the definition of a serious safety warning on the way that Health Canada displayed the information (bolded black print or boxed text, or both). However, the criteria Health Canada uses to develop its safety warnings and the emphasis it places on any particular safety issue are vague. One Health Canada document states "Regulatory actions ... are taken according to the regulatory framework in place. This implies an evaluation of the signal and the appropriate benefit-risk review of the information available." ${ }^{23}$

Second, we could not evaluate whether differences in the detection of safety problems was a reflection of the number of people exposed to the drug in premarket trials, because the Summary Basis of Decision documents do not reliably report population sizes in pivotal trials. ${ }^{24}$

The final limitation is that all of the surrogate outcomes were treated equally and not assessed for their validity. This would be difficult to accomplish in many cases, as the example of diseasefree progression in cancer illustrates, where it seems to be valid for some cancers and not for others. Using an increase in CD4 cell count in HIV as a surrogate for improved survival can present difficulties in interpretation. A 1993 review looked at 16 trials of drug therapy for HIV that used the CD4 cell count as a surrogate outcome. ${ }^{25}$ An increase in cell count was significantly favourable in 7 of the 8 trials in which treatment improved the clinical outcome of progression to AIDS or death. But at the same time, there was also an increase in CD4 cell count in 6 of the 8 trials in which treatment did not retard progression to AIDS or death. ${ }^{1}$ Although the 6-minute walk test was initially considered a valid surrogate marker in pulmonary hypertension, there are now calls for clinical trials to use primary outcomes that reflect long-term disease progression and morbidity. ${ }^{26}$

In some cases, the use of surrogate outcomes is reasonable, because clinical outcomes would present a major barrier to conducting trials. Such cases include amyotrophic lateral sclerosis

Table 1: Therapeutic indications for drugs approved by Health Canada from January 2005 to December 2014, by outcome and approval type

\begin{tabular}{|c|c|c|c|c|c|c|}
\hline \multirow[b]{3}{*}{ Therapeutic indication } & \multicolumn{6}{|c|}{ Outcome and approval process; no. of drugs approved } \\
\hline & \multicolumn{3}{|c|}{ Clinical outcome } & \multicolumn{3}{|c|}{ Surrogate outcome } \\
\hline & Standard & Priority & $\mathrm{NOC} / \mathrm{c}$ & Standard & Priority & $\mathrm{NOC} / \mathrm{c}$ \\
\hline Allergy & 3 & 0 & 0 & 0 & 0 & 0 \\
\hline Cancer & 7 & 9 & 0 & 15 & 9 & 12 \\
\hline Cardiovascular & 2 & 2 & 0 & 5 & 0 & 1 \\
\hline Dermatology & 6 & 0 & 0 & 0 & 0 & 0 \\
\hline Genitourinary & 6 & 0 & 0 & 0 & 0 & 0 \\
\hline Gastrointestinal & 6 & 1 & 0 & 0 & 0 & 0 \\
\hline Gynecology & 2 & 0 & 0 & 1 & 0 & 0 \\
\hline Hematology & 5 & 0 & 0 & 4 & 2 & 1 \\
\hline Inborn error of metabolism & 0 & 1 & 0 & 3 & 2 & 0 \\
\hline Infectious disease, hepatitis & 0 & 0 & 0 & 0 & 6 & 0 \\
\hline Infectious disease, HIV & 0 & 0 & 0 & 4 & 2 & 3 \\
\hline Infectious disease, other & 12 & 2 & 1 & 0 & 0 & 0 \\
\hline Infectious disease, vaccine & 3 & 1 & 0 & 6 & 2 & 0 \\
\hline Metabolic disease, diabetes & 0 & 0 & 0 & 9 & 0 & 0 \\
\hline Metabolic disease, other & 0 & 0 & 0 & 10 & 3 & 0 \\
\hline Miscellaneous & 6 & 1 & 0 & 0 & 0 & 1 \\
\hline Musculoskeletal & 3 & 0 & 0 & 0 & 0 & 0 \\
\hline Neurology & 16 & 1 & 0 & 1 & 0 & 0 \\
\hline Ophthalmology & 2 & 2 & 0 & 2 & 1 & 0 \\
\hline Psychiatry & 13 & 0 & 0 & 0 & 0 & 0 \\
\hline Pulmonary hypertension & 1 & 1 & 0 & 2 & 1 & 0 \\
\hline Respirology & 2 & 0 & 0 & 5 & 1 & 0 \\
\hline Rheumatology & 6 & 1 & 0 & 0 & 0 & 0 \\
\hline Total & 101 & 22 & 1 & 67 & 29 & 18 \\
\hline
\end{tabular}




\section{OPEN}

Research

Table 2: Examples of clinical and surrogate outcomes used to approve drugs, by therapeutic indication

\begin{tabular}{|c|c|c|}
\hline Therapeutic indication & Clinical outcome & Surrogate outcome \\
\hline Allergy & $\begin{array}{l}\text { Bulbar conjunctival injection and ocular itching } \\
\text { (seasonal allergic conjunctivitis) }\end{array}$ & No drugs approved \\
\hline Cancer & Duration of survival (metastatic colorectal cancer) & $\begin{array}{l}\text { Proportion of patients who achieved complete } \\
\text { response or partial response (Hodgkin lymphoma) }\end{array}$ \\
\hline Cardiovascular & $\begin{array}{l}\text { Time to first event of cardiovascular death, } \\
\text { myocardial infarction and stroke (acute coronary } \\
\text { syndromes) }\end{array}$ & $\begin{array}{l}\text { Change from baseline in trough sitting diastolic } \\
\text { blood pressure (hypertension) }\end{array}$ \\
\hline Dermatology & $\begin{array}{l}\text { Change in total inflammatory lesions in adults } \\
\text { (rosacea) }\end{array}$ & No drugs approved \\
\hline Genitourinary & $\begin{array}{l}\text { Number of incontinence episodes per week } \\
\text { (overactive bladder) }\end{array}$ & No drugs approved \\
\hline Gastrointestinal & $\begin{array}{l}\text { No emetic episode and no rescue medication } \\
\text { within } 24 \text { hours (emetogenic chemotherapy) }\end{array}$ & No drugs approved \\
\hline Gynecology & $\begin{array}{l}\text { Percentage of women with a reduction in uterine } \\
\text { bleeding (uterine fibroids) }\end{array}$ & $\begin{array}{l}\text { At least one follicle } \geq 17 \mathrm{~mm} \text {, pre-ovulatory } \\
\text { estradiol serum level } \geq 109 \mathrm{pg} / \mathrm{mL}(400 \mathrm{pmol} / \mathrm{L}) \text {, } \\
\text { and mid-luteal phase progesterone level } \geq 7.9 \mathrm{ng} / \\
\mathrm{mL}(25 \mathrm{nmol} / \mathrm{L}) \text { (follicular development) }\end{array}$ \\
\hline Hematology & $\begin{array}{l}\text { Annualized bleeding rate per patient (congenital } \\
\text { factor IX deficiency) }\end{array}$ & $\begin{array}{l}\text { Proportion of patients who experienced a } \\
\text { hemoglobin response (anemia associated with } \\
\text { chronic kidney disease) }\end{array}$ \\
\hline Inborn error of metabolism & $\begin{array}{l}\text { Proportion of patients alive and free of invasive } \\
\text { ventilator support (Pompe disease) }\end{array}$ & $\begin{array}{l}\text { Reduction in mean spleen volume (type } 1 \text { Gaucher } \\
\text { disease) }\end{array}$ \\
\hline Infectious disease, hepatitis & No drugs approved & Cell histology (hepatitis B) \\
\hline Infectious disease, HIV & No drugs approved & $\begin{array}{l}\text { Proportion of patients with a treatment response } \\
\geq 1 \text { log10 reduction in viral load (HIV) }\end{array}$ \\
\hline Infectious disease, other & $\begin{array}{l}\text { Improvement in respiratory symptoms (cystic } \\
\text { fibrosis) }\end{array}$ & No drugs approved \\
\hline Infectious disease, vaccine & $\begin{array}{l}\text { Protecting against severe rotavirus gastroenteritis } \\
\text { episodes (rotavirus gastroenteritis) }\end{array}$ & $\begin{array}{l}\text { Ability to induce antibodies against viral } \\
\text { hemagglutinin (influenza) }\end{array}$ \\
\hline Metabolic disease, diabetes & No drugs approved & $\begin{array}{l}\text { Change in glycosylated hemoglobin (type } 2 \\
\text { diabetes) }\end{array}$ \\
\hline Metabolic disease, other & No drugs approved & $\begin{array}{l}\text { Percent change in serum low-density lipoprotein } \\
\text { cholesterol concentration (Frederickson type Ila } \\
\text { familial hyperlipidemia) }\end{array}$ \\
\hline Miscellaneous & $\begin{array}{l}\text { Time to onset of relief of symptoms of abdominal } \\
\text { or facial attack (hereditary angioedema) }\end{array}$ & $\begin{array}{l}\text { Complete or partial cytogenetic response } \\
\text { (graft-versus-host disease) }\end{array}$ \\
\hline Musculoskeletal & $\begin{array}{l}\text { Pain intensity, patient's global assessment of } \\
\text { disease activity, and the total score of the Western } \\
\text { Ontario and McMaster Universities questionnaire } \\
\text { (osteoarthritis of knee) }\end{array}$ & No drugs approved \\
\hline Neurology & $\begin{array}{l}\text { Median percent reduction in seizure frequency } \\
\text { (epilepsy) }\end{array}$ & Biochemical marker $8 \mathrm{OH} 2 \mathrm{dG}$ (Friedreich ataxia) \\
\hline Ophthalmology & $\begin{array}{l}\text { Proportion of patients who maintained vision } \\
\text { (macular degeneration) }\end{array}$ & $\begin{array}{l}\text { Change from baseline in anterior chamber cell } \\
\text { grade (anterior uveitis) }\end{array}$ \\
\hline Psychiatry & $\begin{array}{l}\text { Positive and Negative Syndrome Scale total score } \\
\text { (schizophrenia) }\end{array}$ & No drugs approved \\
\hline Pulmonary hypertension & $\begin{array}{l}\text { Time to first occurrence of morbidity or mortality } \\
\text { event (pulmonary arterial hypertension) }\end{array}$ & $\begin{array}{l}\text { Distance covered in 6-minute walking test } \\
\text { (pulmonary hypertension) }\end{array}$ \\
\hline Respirology & $\begin{array}{l}\text { Annual rate of moderate and severe exacerbations } \\
\text { (chronic obstructive lung disease) }\end{array}$ & $\begin{array}{l}\text { Forced expiratory volume in } 1 \text { second and peak } \\
\text { expiratory flow (asthma) }\end{array}$ \\
\hline Rheumatology & $\begin{array}{l}\text { Proportion of patients with an ACR20 response } \\
\text { (rheumatoid arthritis) }\end{array}$ & No drugs approved \\
\hline
\end{tabular}


and some forms of cancer that are uniformly fatal and lack effective therapy, rare diseases for which validation of hard outcomes may take an unreasonable time to complete, and situations where it is ethically impossible to test candidate drugs (e.g., for treatment after exposure to biological or chemical weapons). ${ }^{2}$

\section{Conclusion}

Based on the metrics used in this study, we found no statistically significant difference in postmarket safety between drugs approved on the basis of clinical outcomes and those approved on the basis of surrogate outcomes. Because drugs in the surrogate outcome group are approved before their benefit:harm ratio is fully established, these drugs should be used with caution until their clinical benefits are better understood.

\section{References}

1. Fleming TR, DeMets D. Surrogate end points in clinical trials: Are we being misled? Ann Intern Med 1996;125:605-13.

2. Svensson S, Menkes D, Lexchin J. Surrogate outcomes in clinical trials: a cautionary tale. FAMA Intern Med 2013;173:611-2

3. Connolly HM, Crary J, McGoon M, et al. Valvular heart disease associated with fenfluramine-phentermine. N Engl 7 Med 1997;337:581-8.

4. Echt DS, Liebson PR, Mitchell LB, et al. Mortality and morbidity in patients receiving encainide, flecainide, or placebo. The Cardiac Arrhythmia Suppression Trial. NEngl 7 Med 1991;324:781-8.

5. Nissen SE, Wolski K. Effect of rosiglitazone on the risk of myocardial infarction and death from cardiovascular causes. N Engl 7 Med 2007;356:2457-71.

6. Lexchin J. New drugs and safety: What happened to new active substances approved in Canada between 1995 and 2010? Arch Intern Med 2012;172: 1680-1.

7. Lexchin J. Postmarket safety warnings for drugs approved in Canada under the Notice of Compliance with conditions policy. Br 7 Clin Pharmacol 2015;79: 847-59 [published online 2014 Nov. 12]

8. Evaluation of biomarkers and surrogate endpoints in chronic disease. Washington (DC): Institute of Medicine; 2010.

9. Therapeutic Products Programme Guideline: preparation of human new drug submissions. Ottawa: Health Canada; 1991. Available: http://publications.gc.ca/collections/ collection 2013/sc-hc/H42-2-38-1991-eng.pdf (accessed 2015 Feb. 10).

10. Carpenter D, Zucker E, Avorn J. Drug-review deadlines and safety problems. NEngl7 Med 2008;358:1354-61.

11. Berlin RJ. Examination of the relationship between oncology drug labeling revision frequency and FDA product categorization. Am 7 Public Health 2009; 99:1693-8.

12. Ciani O, Buyse M, Garside R, et al. Comparison of treatment effect sizes associated with surrogate and final patient relevent outcomes in randomised controlled trials: meta-epidemiological study. BM7 2013;346:f457.

13. Clement FM, Harris A, Li J, et al. Using effectiveness and cost-effectiveness to make drug coverage decisions: a comparison of Britain, Australia, and Canada. 7AMA 2009;302:1437-43.

14. Downing NS, Aminawung J, Shah N, et al. Clinical trial evidence supporting FDA approval of novel therapeutic agents, 2005-2012. 7AMA 2014;311: 368-77.

15. Ujeyl M, Schlegel C, Walter S, et al. New drugs: evidence relating to their therapeutic value after introduction to the market. Dtsch Arztebl Int 2012;109: 117-23.

16. Apolone G, Joppi R, Bertele V, et al. Ten years of marketing approvals of anticancer drugs in Europe: regulatory policy and guidance documents need to find a balance between different pressures. Br 7 Cancer 2005;93:504-9.

17. Johnson JR, Ning YM, Farrell A, et al. Accelerated approval of oncology products: the Food and Drug Administration experience. 7 Natl Cancer Inst 2011; 103:636-44.

18. Garattini S, Bertele V. Efficacy, safety, and cost of new anticancer drugs. BMF 2002;325:269-71.

19. Venook AP, Tabernero J. Progression-free survival: Helpful biomarker or clinically meaningless end point? $\mathcal{F}$ Clin Oncol 2015;33:4-6.

20. Cheema PK, Burkes R. Overall survival should be the primary endpoint in clinical trials for advanced non-small-cell lung cancer. Curr Oncol 2013;20: e150-60.

21. Han K, Ren M, Wick W, et al. Progression-free survival as a surrogate endpoint for overall survival in glioblastoma: a literature-based meta-analysis from 91 trials. Neuro-oncol 2014;16:696-706.

22. Yudkin JS, Lipska K, Montori V. The idolatry of the surrogate. BMf 2011;343:d7995.

23. How adverse reaction information on health products is used. Ottawa: Marketed Health Products Directorate; 2004.

24. Habibi R, Lexchin J. Quality and quantity of information in Summary Basis of Decision documents issued by Health Canada. PLoS ONE 2014;9:e92038.

25. Sande MA, Carpenter C, Cobbs C, et al. Antiretroviral therapy for adult HIV infected patients. Recommendations from a state-of-the-art conference. National Institute of Allergy and Infectious Diseases state-of-the-art panel on anti-retroviral therapy for adult HIV-infected patients. FAMA 1993;270:2583-9.

26. Gaine S, Simonneau G. The need to move from 6-minute walk distance to outcome trials in pulmonary arterial hypertension. European Respiratory Review $2013 ; 22: 487-94$

Affiliations: School of Health Policy and Management (Lexchin), York University; Emergency Department (Lexchin), University Health Network; Department of Family and Community Medicine (Lexchin), University of Toronto, Toronto, Ont.; Faculty of Health Sciences (Ahmed), Simon Fraser University, Burnaby, BC; Drug Assessment Working Group (Ahmed), Therapeutics Initiative, University of British Columbia, Vancouver, BC

Contributors: Joel Lexchin designed the trial and wrote the first draft of the manuscript. Both authors contributed to the acquisition and analysis of data, revised the manuscript for intellectual content, approved the final version to be published and agreed to act as guarantors of the work.

Supplemental information: For reviewer comments and the original submission of this manuscript, please see www.cmajopen.ca/content/3/3/ E286/suppl/DC1 